NIH as officers in the U.S. Public Health Service Commissioned Corps to fulfill their Selective Service obligation) were trained and developed scientific maturity and independence before pursuing research careers.

The best attraction to a clinical research career may be the promise to a physician of committed funding to conduct the clinically oriented or basic research of his or her choice. Goldstein and Brown argue that the best science done by physician-scientists occurs in an atmosphere that is not oriented to clinical outcomes but seeks only to elucidate basic biologic processes. ${ }^{4}$ Jeffrey Flier, dean of the Faculty of Medicine at Harvard Medical School, notes that it's the confluence of talented indi- viduals and "magical" research opportunities at the NIH that enables success. ${ }^{5}$ The major contributions that clinically trained scientists have made to our understanding of human biology have come not from anything unique about their research skills, but rather from their perspective derived from clinical experience or training that enables them to define and pursue important problems in human biology, especially in a highly supportive research environment.

The NIH hopes to serve as a catalyst for a national effort to nurture clinician-scientists by providing such varied opportunities in an incubator-like environment, by demonstrating the value of investing in protected research time, and by inspiring partnerships and complementary clinically oriented research programs at major institutions.

Disclosure forms provided by the author are available with the full text of this article at NEJM.org.

From the National Institutes of Health, Bethesda, MD.

This article was published on May 15, 2013, at NEJM.org.

1. Wyngaarden JB. The clinical investigator as an endangered species. N Engl J Med 1979;301:1254-9.

2. Schafer Al, ed. The vanishing physicianscientist? Ithaca, NY: Cornell University Press, 2009.

3. Ley TJ, Rosenberg LE. The physicianscientist career pipeline in 2005: build it, and they will come. JAMA 2005;294:1343-51.

4. Goldstein JL, Brown MS. A golden era of Nobel laureates. Science 2012;338:1033-4.

5. Flier JS. Creating a Nobel culture. Science 2013;339:140-1.

DOI: 10.1056/NEJMp1302969

Copyright $\odot 2013$ Massachusetts Medical Society.

\title{
Assessing Competency for Concealed-Weapons Permits The Physician's Role
}

Adam O. Goldstein, M.D., M.P.H., Kathleen K. Barnhouse, M.D., Anthony J. Viera, M.D., M.P.H., James A. Tulsky, M.D., and Barak D. Richman, J.D., Ph.D.

hortly after the shootings in $\checkmark$ Newtown, Connecticut, two of us received letters from our county sheriff in North Carolina asking whether one of our patients had medical or physical conditions that would preclude issuance of a permit to carry a concealed weapon. Uncomfortable with our limited knowledge about such permits and our expected role, and fearing that our participation could affect our relationships with patients, we began exploring the ethical, legal, and policy considerations regarding physician involvement in this process.

Although the U.S. Supreme Court recently held that the Second Amendment protects an in- dividual's right to possess guns for traditionally lawful purposes, that right is subject to reasonable legislative limitations. Federal law, for example, prohibits gun sales to felons, persons found to abuse controlled substances, persons with a history of domestic violence, and persons deemed dangerously mentally ill. The Brady Law requires background checks for gun purchases from federally licensed dealers.

Although denying weapons to people with prior convictions seems relatively straightforward, it's more difficult to assess mental competence and current or future risk for violence. Even with drug testing, it's often difficult to detect clinically whether a person is abusing illegal substances, controlled prescription drugs, or alcohol. Waiting periods for gun purchases vary by state, and sales by private parties require no background checks or substance-abuse clearance.

Every U.S. state allows some persons to carry certain concealed weapons in public, after varied approval processes. States also vary on who, if anyone, has the authority to deny gun permits to individuals - some states prohibit denial if certain criteria are met; others allow law-enforcement agencies to deny permits regardless. The number of permit applications for concealed weap- 
ons has surged - in Florida, for instance, from 28,618 in 2000 to more than 150,000 in 2011 , and in Michigan from 29,914 in 2003 to more than 90,000 in $2010 .^{1,2}$ Many states require local lawenforcement agencies to sign off on concealed-weapons permits, and applicants must disclose mental or physical conditions that could interfere with safe weapon handling. Local law-enforcement officers may require applicants to provide the name of a physician who can attest to any aspect of their physical or mental health history that might make it inadvisable to allow them to have a concealed weapon.

For those physicians, several concerns arise. First, assessment of competency requires training and standards, but no physician training programs or standards exist. Even professional recommendations that physicians assess whether patients are at increased risk for committing gun violence are rarely followed. ${ }^{3}$ Moreover, there's no evidence that physicians can accurately assess patients' ability to use weapons competently and safely.

Although physicians can complete checklists about physical or mental health diagnoses, it's unclear whether they can reliably prognosticate about the safety of a patient's decision to carry a concealed weapon, a critical issue for assessing competency. For instance, since 2005, more than 150 people who received permits to carry concealed weapons in Michigan have committed suicide. ${ }^{2}$ In North Carolina, over a 5-year period, more than 2400 permit holders were convicted of crimes, including 900 drunk-driving offenses and more than 200 felonies. ${ }^{4}$ Given the number of patients with at least one condition that might affect their physical or mental function, it's difficult to see how physicians can assess safety in the absence of comprehensive standards. Instead, physicians may choose whether to sign off on such permits guided as much by their own views about gun ownership as by any standard.

An analogous situation arises from the requirement for medical clearance for issuance of commercial motor vehicle licenses. The Department of Transportation, however, has issued detailed regulations about who is considered a licensed medical examiner for "transportation" physicals, the duration for which clearance is granted, and conditions that might affect safety, including musculoskeletal, cardiac, respiratory, neurologic, endocrine, emotional, and psychiatric conditions. Applicants for commercial driver's licenses must schedule a physician's appointment, which is treated as an office visit and billed appropriately. The physician may recommend repeat assessments - for instance, for patients with severe hypertension or arthritis. In contrast, the forms that physicians are asked to fill out for concealedweapons permit applications lack details on what to assess or disclose and vary substantially among jurisdictions.

Second, there may well be substantial variation in what is considered to constitute mental and physical competence to carry a concealed weapon. Reasonable physicians might disagree about whether patients with Parkinson's disease, prior strokes, atrial fibrillation, seizures, or chronic pain are physically com- petent to use a weapon safely, as well as about whether people who have a history of depression, substance or alcohol abuse, anxiety, or insomnia or who are taking psychotropic medications are mentally competent to do so. Guidance is needed regarding the need and protocols for collection of urine toxicology or blood alcohol reports to rule out drug or alcohol use before signing off on permits.

Third, requests to sign off on concealed-weapons permits may raise ethical questions for physicians. For instance, should physicians disclose personal information about the patient's childhood, such as a history of sexual abuse? Many physicians may see any participation in concealed-weapons approval as unethical, since it doesn't serve a primary goal of medicine and may violate their religious beliefs. (Such conscientious objection resembles that of physicians with religious objections to providing contraception to single women.) If physicians don't wish to participate in these assessments, they can inform lawenforcement agencies, although they may fear that not signing a permit would damage their physician-patient relationship.

Fourth, several legal issues need clarification. When physicians convey private health information to the state, they're potentially vulnerable to liability claims under the Health Insurance Portability and Accountability Act. Clinicians have been sued for releasing records about patients' mental health even in response to subpoenas. ${ }^{5}$ There is also a threat of tort liability. Although many states provide immunity to liability for lawenforcement officials who make 
determinations about concealedweapons permits, participating physicians may not have immunity. Some people who have been granted such permits have killed and injured others, ${ }^{4}$ and in most cases, their applications should have been denied. When physicians sign off on permits, do they share liability for these deaths? If a patient obtains a permit but is subsequently found to have a psychological or physical condition that precludes safe or competent weapon use, must the physician contact law enforcement - just as physicians in some states must report to the department of motor vehicles medical conditions that may preclude an ability to drive safely? Clarifying the physician's role might help alleviate concerns about liability. For example, if police contracted with physicians for assessments, physicians would be agents of the state and more likely to be protected from liability. Finally, perhaps new legislation might expand gun-free zones to include all health care settings.

Moving forward, we believe policymakers and physicians' organizations should consider several issues. Federal legislation or rule making could help define national standards and guidelines on what constitutes mental and physical competence to carry a concealed weapon and who can make those assessments. Additional research can help establish standards, along with protocols to assess and test for substance abuse, with input from physicians and public health and legal experts. Using these standards, physicians could review patients' health histories, conduct physical examinations and laboratory testing, and recommend appropriate intervals for reassessments. If a patient's physician declined to participate, the patient could be referred to a physician contracted by the law-enforcement agency who was trained in making such assessments.

We also believe that medical education should incorporate broader violence-prevention training that might resemble training for assessments of disability or competency for safe driving of commercial vehicles. Finally, policymakers and professional organizations should consider modifying legislation to prohibit carrying concealed weapons in clinical settings and should examine ways of limiting the liability of physicians who follow appropriate standards, once such standards exist.
Disclosure forms provided by the authors are available with the full text of this article at NEJM.org.

From the Department of Family Medicine, University of North Carolina School of Medicine, Chapel Hill (A.O.G., K.K.B, A.J.V.); and the Department of Medicine, Duke University School of Medicine (J.A.T.), and Duke University School of Law (B.D.R.), Durham, NC.

This article was published on April 17, 2013, at NEJM.org.

1. Michigan State Police Criminal Justice Information Center. Concealed pistol licensure annual report: July 1, 2009 to June 30, 2010 (http://www.michigan.gov/documents/msp/ 2009-10_CPL_Annual_Report_343621_7 .pdf).

2. Florida Department of Agricultural and Consumer Services, Division of Licensing. New Florida concealed weapon license applications, fiscal year 1999-2000 through fiscal year 2011-2012 (http://licgweb.doacs .state.fl.us/stats/CWApplications ReceivedByFiscalYearSince1999-2000.pdf). 3. Price JH, Thompson A, Khubchandani J, Wiblishauser M, Dowling J, Teeple K. Perceived roles of emergency department physicians regarding anticipatory guidance on firearm safety. J Emerg Med 2013 January 23 (Epub ahead of print).

4. Webster DW, Vernick JS, Vittes K, McGinty EE, Teret SP, Frattaroli S. The case for gun policy reforms in America. Baltimore: John Hopkins Bloomberg School of Public Health, October 2012 (http://www.jhsph.edu/ research/centers-and-institutes/johns-hopkins -center-for-gun-policy-and-research/ publications/WhitePaper102512_CGPR.pdf). 5. Turk vs Oiler. Case No.:09-cv-381-KMO 2010 (http://www.gpo.gov/fdsys/pkg/ USCOURTS-ohnd-1_09-cv-00381).

DOI: 10.1056/NEJMp1302795

Copyright $\odot 2013$ Massachusetts Medical Society.

\section{Health Promotion and the State}

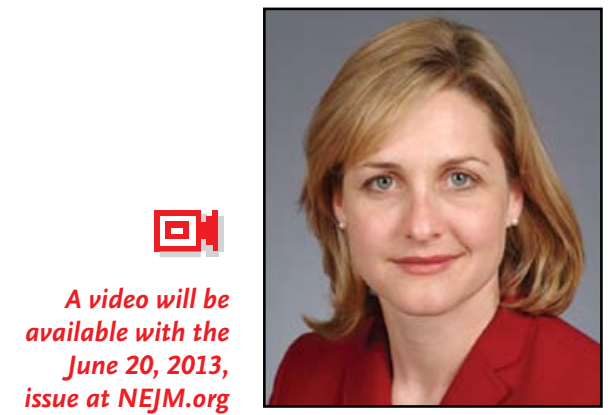

Some major U.S. public health problems are perpetuated and exacerbated at least in part by lifestyle choices and individual behavior. Policymakers at all levels of government are struggling to find ways of intervening to promote wellness and reduce unhealthy behaviors without overstepping the limits of their authority or infringing on personal liberties. What can and should government do to reduce obesity and tobacco use? On May 17, 2013, experts Thomas Farley, Steven Gortmaker, and Cass Sunstein addressed these and other questions about health promotion and the state in a roundtable discussion moderated by Meredith Rosenthal. 